\title{
OFICINA DE BARALHO MATEMÁTICO: UMA PROPOSTA LÚDICA PARA O ENSINO-APRENDIZAGEM DAS OPERAÇÕES BÁSICAS
}

\section{TALLER DE MATEMÁTICAS: UNA PROPUESTA DIVERTIDA PARA ENSEÑAR Y APRENDER DE OPERACIONES BÁSICAS}

\section{MATHING WORKSHOP: A FUN PROPOSAL FOR TEACHING AND LEARNING OF BASIC OPERATIONS}

\author{
Wesley Matheus Moura Balbino ${ }^{1}$; Cleiton Pedrosa de Sales ${ }^{2}$; Pedro Alexandre \\ Linhares Lima ${ }^{3}$ Iago Reis Santos ${ }^{4}$; Francismar Holanda ${ }^{5}$
}

DOI: $\underline{\text { https://doi.org/10.31692/978-65-991061-3-2.140-145 }}$

\section{INTRODUÇÃO}

Muitos são os desafios encontrados em relação ao aprendizado de matemática, e isso é notório quando nos deparamos com alunos de vários cursos de nível superior fazendo os seguintes questionamentos: "para que vou usar isso?", "será se vou precisar mesmo disso na minha vida?”, “o que isso tem haver com meu curso?”. Isso podemos observar com frequência no decorrer da graduação. Sabemos também que desde cedo a matemática é vista como uma disciplina complexa e que quem domina é considerado superdotado, essa ideia é reforçada pelo modelo tradicional de ensino, fazendo com que muitos procurem por cursos que aparentemente não possuem matemática na sua grade curricular.

\begin{abstract}
É muito comum observarmos nos estudantes o desinteresse pela matemática, o medo da avaliação, pode ser contribuído, em alguns casos, por professores e pais para que esse preconceito se acentue. Os professores na maioria dos casos se preocupam muito mais em cumprir um determinado programa de ensino do que em levantar as ideias prévias dos alunos sobre um determinado assunto. Os pais revelam aos filhos a dificuldade que também tinham em aprender matemática, ou até mesmo escolheram uma área para sua formação profissional que não utilizasse matemática. (SANTOS, 2007, apud, VITTI, 1999, p.32/33).
\end{abstract}

É nesse sentido que, o presente trabalho foi realizado com o intuído de reforçar os conhecimentos básicos de matemática através de um jogo de cartas envolvendo operações como: adição, subtração, multiplicação, divisão, potenciação e radiciação dos alunos dos módulos iniciais dos cursos de Licenciatura em Biologia, Química e Matemática do Instituto Federal de Educação, Ciência e Tecnologia do Piauí - Campus Teresina Central.

\section{FUNDAMENTAÇÃO TEÓRICA}

\footnotetext{
${ }^{1}$ Licenciatura em matemática, Instituto Federal do Piauí - Teresina Central, wesleymathifpi@gmail.com

${ }^{2}$ Licenciatura em matemática, Instituto Federal do Piauí - Teresina Central, cleitonsales1995@ gmail.com

${ }^{3}$ Licenciatura em matemática, Instituto Federal do Piauí - Teresina Central, pedroalexandre406@gmail.com

${ }^{4}$ Licenciatura em matemática, Instituto Federal do Piauí - Teresina Central, iagobtf75@gmail.com

${ }^{5}$ Mestre, Instituto Federal do Piauí - Campus Teresina Central, frholanda@ifpi.edu.br
} 
No modelo tradicional de ensino, muita das vezes, só há um caminho, ou método, do qual o aluno acha que deva seguir para se alcançar o resultado esperado. Entretanto quando isso não acontece, ele acaba se desestimulando e desistindo de aprender determinado conteúdo, levando-o a prosseguir com lacunas no decorrer de sua vida acadêmica. A ideia de se criar um baralho matemático surgiu no sentido de aproveitar a competitividade que há nos jogos, o que gera um interesse maior em se aprender o que se está jogando e, consequentemente, o fortalecimento de alguns conceitos básicos relacionados à matemática.

É bastante comum o aluno desistir de solucionar um problema matemático, afirmando não ter aprendido como resolver aquele tipo de questão ainda, quando ela não consegue reconhecer qual o algoritmo ou processo de solução apropriado para aquele problema. Falta aos alunos uma flexibilidade de solução e a coragem de tentar soluções alternativas, diferentes das propostas pelos professores. (D’AMBROSIO, 1989, p.1).

Contudo os alunos, em sua maioria, não conseguem ter essa pré-disposição para usarem outras ferramentas que possam lhes ajudar a apropriar-se do conteúdo, cabendo ao professor chamar essa responsabilidade para si. O baralho matemático aparece como uma ferramenta que amplia as possibilidades de aprendizagem e fixação dos conteúdos debilitados nos alunos.

O lúdico permite o prazer e a satisfação pelo ato de jogar, ao jogar procura sempre superar o desafio, o que motiva e incentiva a busca pelo saber de forma prazerosa e interativa; já sobre o papel educativo, o jogo educa para experiências sociais em um mundo, que possui leis e regras que precisam ser conhecidas e internalizadas. Além disso, o jogo estimula o desenvolvimento cognitivo, e auxilia na criação de estratégias para a solução de possíveis problemas que surgem no decorrer do processo de aprendizagem. (SILVA, 2015, p.4)

Santos (2015, p.106) afirma: "a escola precisa ser repensada com vistas a criar vários espaços onde o aluno possa aprender a partir de uma aula expositiva, uma roda de debate, uma leitura, a fim de experimentar aquilo que aprendeu na teoria”.

\section{METODOLOGIA}

O jogo intitulado de "Baralho de Matemática" teve a sua aplicação durante uma oficina realizada no âmbito da disciplina de Projeto Integrador IV (PI-IV) com o intuito de contribuir de forma satisfatória para a apropriação de conteúdos básicos de matemática por parte dos alunos do curso de Licenciatura em Biologia, Química e Matemática.

O público alvo da oficina foi composto por 15 (quantidade de alunos total), sendo 5 alunos de Licenciatura em Biologia, 5 alunos de Química e 5 alunos da matemática 
A oficina ocorreu em três momentos. O primeiro momento foi composto pela elaboração das regras do jogo e definição dos materiais utilizados na oficina. O segundo momento foi a oficina de fato, na qual os alunos tiveram uma breve explanação dos conteúdos abordados dentro do Baralho e uma introdução as regras do jogo. O Terceiro de último momento foi composto pela construção do material por parte dos alunos seguido da parte lúdica da oficina (o jogo).

O jogo é composto por 52 cartas, distribuídas em 4 cores distintas, com operações matemáticas com resultado variando de 2 a 13, além de possuir uma carta coringa que assume o valor de 1 .

As regas do jogo foram definidas da seguinte forma:

1. O jogo deve ser jogado por um grupo mínimo de duas pessoas e máximo de quatro pessoas;

2. Cada jogador inicia com três cartas na mão;

3. O aluno pode escolher parar ou continuar pegando cartas;

4. Vence o jogador que possuir o valor mais próximo de 21;

5. Caso todos os jogadores ultrapassem o valor de 21 , vence quem tiver o menor valor em mãos.

Após realizado a aplicação do jogo, foi aplicado um questionário composto por três perguntas, sendo elas: o Baralho de Matemática foi eficiente na consolidação de conteúdos básicos referentes ao ensino de matemática?; Na sua visão de professor, a utilização de recursos lúdicos para o ensino de matemática é válida?; A oficina teve um papel importante na sua formação acadêmica? E todas as perguntas deveriam ser respondidas com uma nota de 1 a 5 , dependendo do nível de satisfação do aluno participante. Eles também poderiam comentar algo a respeito de cada pergunta se quisessem.

\section{RESULTADOS E DISCUSSÕES}

O trabalho alcançou nossas expectativas, pois percebemos que com o uso do material didático e da competitividade houve maior interesse em aprender as regras do jogo e, consequentemente, o resultado das operações. O gráfico abaixo mostra os resultados das perguntas que foram feitas ao término da oficina. Foi feito a média aritmética das notas atribuídas pelos alunos relacionadas a cada pergunta. A avaliação varia de 0 a 5 , de acordo com o nível de satisfação em que tiveram na oficina. As perguntas foram as seguintes:

- Pergunta 1: o Baralho de Matemática foi eficiente na consolidação de conteúdos básicos 
referentes ao ensino de matemática?

- Pergunta 2: Na sua visão de professor, a utilização de recursos lúdicos para o ensino de matemática é válida?

- Pergunta 3: A oficina teve um papel importante na sua formação acadêmica?

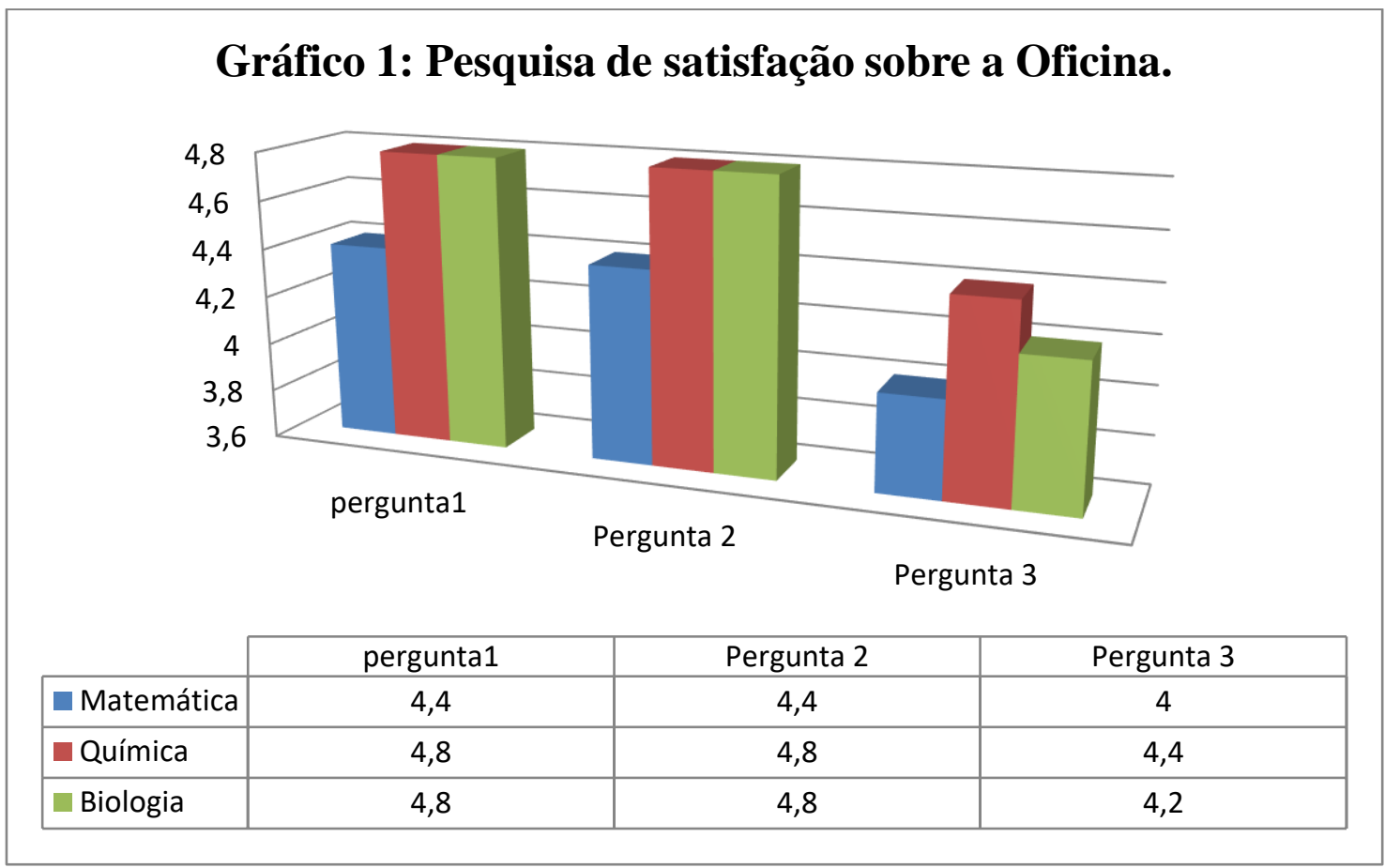

Fonte: Própria (2019).

Alguns alunos quiseram comentaram a respeita da proposta de utilização do Baralho Matemático como ferramenta de ensino. Vejamos a seguir.

- Aluno N (Mat) sobre as três perguntas respectivamente.

Pergunta 1: Sim, gostei. Foi bem eficiente.

Pergunta 2: com certeza, com ela nós podemos expandir nossa didática e aprimorar o entendimento do aluno.

Pergunta 3: foi bem legal, me deu novas ideias para aplicar o ensino da matemática em sala de aula.

- Aluno N (Mat) sobre as três perguntas respectivamente.

Pergunta 1: Sim, pois foi uma maneira lúdico que exercitamos os conteúdos básicos da matemática é consequentemente obtemos o conhecimento de forma prazerosa e mais fácil.

Pergunta 2: Sim, com certeza são uma ferramenta que pode sim complementar bastante no ensino, mais temos que saber utilizá-lo.

Pergunta 3: Sim, pois pude perceber que a utilização de recursos lúdicos pode melhorar o ensino 
do aluno de forma significativa.

- Aluno B (Bio) sobre as três perguntas respectivamente.

Pergunta 1: Sim, de uma forma bem divertida sem perder o real sentido de ensino-aprendizagem (pelo menos foi o q achei).

Pergunta 2: Sim, acredito ser bastante eficiente em uma disciplina que considerada de difícil aprendizagem, pois eu tive e tenho bastante dificuldade com a mesma.

Pergunta 3: Sim, tive a oportunidade de relembrar alguns conteúdos.

- Aluno D (Bio) sobre as três perguntas respectivamente.

Pergunta 1: Sim.

Pergunta 2: Sim, facilita a compreensão do assunto, e é uma maneira divertida de aprender.

Pergunta 3: Sim, porque vendo exemplos é ate uma maneira de estimular as pessoas(os outros, futuros docentes) a utilizarem esse recurso, porque foi muito legal.

- Aluno A (Bio) sobre as três perguntas respectivamente.

Pergunta 1: Sim, pois notei que estava bem elaborado, além da explicação ter sido clara, o que acarretou num boa compreensão dos conteúdos.

Pergunta 2: Extremamente válida, pois sabemos que os alunos comumente apresentam dificuldade de compreensão da disciplina, e com o uso do lúdico, se torna mais simples a compreensão dos conteúdos, além de apresentar-se mais interessante, despertando a curiosidade dos alunos.

Pergunta 3: Sim, pois como futura professora de ciências e biologia, entender conceitos básicos de matemática é essencial para desenvolver com futuros alunos conteúdos como genética, por exemplo.

\section{CONCLUSÕES}

Podemos verificar que, através dos dados obtidos, o trabalho teve uma importância significativa para os graduandos que tiveram participação na oficina, onde o relato dos mesmos nos mostra que o uso de recursos didáticos são indispensáveis para a fixação dos conteúdos e para instigar o aluno a pensar por si próprio. O trabalho teve como objetivo fortalecer os conhecimentos prévios e suprir as deficiências trazidas lá do ensino básico, promovendo, assim, um pensamento crítico e desenvolvendo o raciocínio lógico em cada um deles. A experiência acabou tendo certa importância na vida acadêmica dos graduandos, pois além de ter reforçado alguns conteúdos, serviu também para instiga-los a buscar outras ferramentas que poderiam ser usadas para sanar essas dificuldades, o que nos dar mais opções, mostrando que o ensinar pode ser mais diversificado quanto o que é mostrado geralmente em sala de aula. 


\section{REFERÊNCIAS}

D’AmbrosiO, B. S. Como ensinar matemática hoje? Temas e Debates. Ano II, no 2, 1989.

FALCÃO, Paula; VILA, Magda. Focalização de Jogos em T \& D. Qualitymark. RJ, 2008.

SILVA, J. N. Confecção de jogos matemáticos na sala de apoio a aprendizagem com alunos do $6^{\circ}$ ano do ensino fundamental. PDE, 2015.

SANTOS, Glauco de Souza. Espaços de Aprendizagem. In: BACICH, Lilian; NETO, Adolfo Tanzi; TREVISANI, Fernando de Mello (Orgs). Ensino Híbrido: personalização e tecnologia na educação. Porto Alegre: Penso, 2015.

SMOLE, K. S. DINIZ, M. I. MILANI, E. Jogos de matemática de 6o a 9o ano. Porto Alegre: Artmed. (Série Cadernos do Mathema-Ensino Fundamental), 2007.

SAVI, Rafael; ULBRICHT, Vania Ribas. Jogo digitais educacionais: benefícios e desafios. Renote - Revista Novas Tecnologias na Educação, Porto Alegre, v. 6, n. 1, p. 1-10, jul. 2008. Disponível em: http://seer.ufrgs.br/renote/article/view/14405/8310. Acesso em: 25 jun. 2017. 